\title{
Orthographic and Perspective Projection Influences Linear Vection in Large Screen Virtual Environments*
}

\author{
Laura C. Trutoiu ${ }^{\dagger}$ \\ Mount Holyoke College
}

\author{
Silvia-Dana Marin \\ Mount Holyoke College
}

\author{
Betty J. Mohler \\ Max Planck Institute
}

\author{
Claude Fennema \\ Mount Holyoke College
}

\section{Introduction}

Vection is defined as the visually induced illusion of self motion [Fischer and Kornmüller 1930]. Previous research has suggested that linear vection (the illusion of self-translation) is harder to achieve than circular vection (the illusion of self-rotation) in both laboratory settings (typically using 2D stimuli such as black and white stripes) [Rieser 2006] and virtual environment setups [Schulte-Pelkum 2007; Mohler et al. 2005]. In real a life situation when experiencing circular vection all objects rotate around the observer with the same angular velocity. For linear motion, however, the change in the oberver position results in a change in the observed position of closer objects with respect to farther away objects or the background. This phenomenon, motion parallax, provides pictorial depth cues as closer objects appear to be moving faster compared to more distant objects.

\section{Experiments}

We are investigating the effect of depth cues on the perception of linear vection as a first attempt towards isolating the influence of motion parallax on vection. The experimental setup consists of a vection chamber with two lateral windows on either side of the subject on which identical images are projected (see Figure 1).

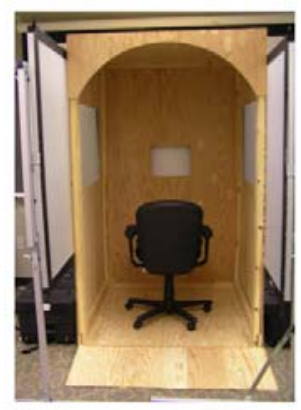

(a) Chamber

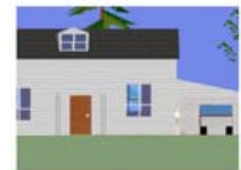

(c) Orthographic

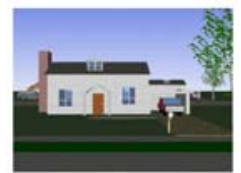

(b) Perspective
Figure 1: Experimental Setup: Back projectors allowed for simultaneous stimulation of the peripheral vision of the participant. Viewing was done under decreased lighting conditions and a constant white noise was used to mask environmental sounds.

Fourteen subjects were pre-screened to determine if they would experience vection while viewing realistic viewing stimulus within this setup. The 12 participants who reported experiencing the sensation of being in a moving vehicle under the pre-screening conditions then participated in the within-subject experiment. The visual

\footnotetext{
* Special thanks Joseph Cohen, William Thompson, and John Rieser.

†e-mail: lctrutoi@mtholyoke.edu
}

stimulus was rendered based on a 3D model of a residential neighborhood consisting of repetitive houses in various depth planes (using Google Sketchup). Each participant experienced 16 trials of visual stimulus within the vection chamber. These 16 trials were divided into two conditions: perspective projection (exhibiting motion parallax) and orthographic (no motion parallax) (see Figure 1). The eight trials per condition also had three different levels of speed and duration of trial; $40 \mathrm{mph}$ for 30 seconds ( 2 trials), $60 \mathrm{mph}$ for 45 seconds( 2 trials), and a combination of the two for 40 seconds using a step function ( 2 trials). For each trial participants were asked to verbally report when, if ever, they experienced vection. Each trial was prefaced with a fifteen second static snapshot of the visual projection that the participant would experience during that trial. This enabled the participant to fixate forward and prevented an aftereffect to influence the subsequent trials.

\section{Results and Discussion}

Participants experienced vection in $84.3 \%$ of the trials for the perspective projection and $55.2 \%$ of the trials when projection was orthographic. Figure 2 shows the percent of trials in which subjects experienced vection according to speed conditions. Average vection onset time for perspective projection was 9.38 seconds, and for orthographic projection average vection onset time was $13.02 \mathrm{sec}-$ onds (see Figure 2). For vection onset analysis we removed the five participants who did not report experiencing vection under orthographic viewing conditions. The vection onset times are consistent with previous results found by [Mohler et al. 2005]. Our results
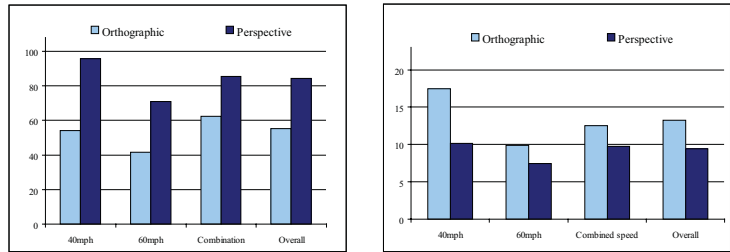

Figure 2: a) Percent of trials where vection was reported based on both speed and projection method. b) Average vection onset time latency in 3 different speed conditions.

show a strong differentiation between the orthographic and perspective conditions. Studying vection in a virtual reality setup allows for extensive exploration in the nature of the graphical information that favor vection. Further data analysis and a study with more participants needs to be conducted in order to determine the combination of the different graphical variables (visual cues) present in the orthographic versus perspective conditions.

\section{References}

Fischer, M. H., AND Kornmüller, A. E. 1930. Optokinetisch ausgel oste bewegungswahrnehmung und optokinetischer nystagmus optokinetically induced motion perception and optokinetic nystagmus. Journal für Psychologie und Neurologie, 273-308

Mohler, B. J., Thompson, W. B., Riecke, B., And Bülthoff, H. H. 2005. Measuring vection in a large screen virtual environment. In Proc. Symposium on Applied Perception in Graphics and Visualization, 103-109.

RIESER, J., 2006. Discussion with Dr. John Rieser.

Schulte-Pelkum, J. 2007. Perception of self-motion: Vection experiments in multisensory virtual environments. unpublished Doctoral Dissertation: Max Planck Institute for Biological Cybernetics.
Permission to make digital or hard copies of part or all of this work for personal or classroom use is granted without fee provided that copies are not made or distributed for commercial advantage and that copies bear this notice and the full citation on the first page. Copyrights for components of this work owned by others than ACM must be honored. Abstracting with credit is permitted. To copy otherwise, to republish, to post on servers, or to redistribute to lists, requires prior specific permission and/or a fee. Request permissions from Permissions Dept, ACM Inc., fax +1 (212) $869-0481$ or e-mail permissions@acm.org.

APGV 2007, Tübingen, Germany, July 26-27, 2007.

(C) 2007 ACM 978-1-59593-670-7/07/0007 $\$ 5.00$ 